Www.jmscr.igmpublication.org

Impact Factor (SJIF): 6.379

Index Copernicus Value: 79.54

ISSN (e)-2347-176x ISSN (p) 2455-0450

crossrefDOI: https://dx.doi.org/10.18535/jmscr/v6i10.80

Journal Of Medical Science And Clinical Research

IGM Publication

An Official Publication of IGM Publication

\title{
Role of VIA and Pap smear of cervix as screening in low resource setting
}

\author{
Authors \\ Dr Helen Kamei ${ }^{*}$, Dr Ratana Usham², Dr Majachunglu Gangmei ${ }^{3}$, \\ Dr Mayanglambam Ronita Devi ${ }^{4}$, Dr Laishram Madhuri Devi ${ }^{5}$, \\ Dr Tenshubam Nimmi Devi ${ }^{6}$, Dr L Umalakshmi Devi ${ }^{7}$ \\ ${ }^{1}$ Associate Professor, Dept of Obgyn, JNIMS, ${ }^{2}$ Assistant Professor, Dept of Obgyn, JNIMS \\ ${ }^{3}$ MO, Manipur, ${ }^{4,5,6,7}$ Senior Resident, Dept of Obgyn, JNIMS \\ *Corresponding Author \\ Dr Helen Kamei \\ Associate Professor, Dept of Obgyn, JNIMS
}

\begin{abstract}
Aim of the study: to compare Visual inspection with acetic acid and pap smear for cervical cancer screening in low resource setting.

Materials and Method: Random women age ranging from 20-70 years were subjected to per speculum examination followed by Pap smear sampling and Visual inspection with acetic acid.

Results: Of the three hundred women examined, 2 cases were diagnosed as having squamous cell carcinoma of the cervix and one case of adenocarcinoma of the cervix. 15 cases were found to have low grade squamous intraepithelial lesion (LSIL), 4 cases had High grade squamous intraepithelial lesion (HSIL) and 31 cases of Atypical squamous epithelium (ASC-H/US). Two cases had smears inadequate for evaluation. The remaining cases were negative for intraepithelial lesion/malignancy (NILM).

Conclusion: There is no denying the momentous role of pap smear in early detection of Premalignant and malignant cervical lesion and effective and timely intervention. However, the handicap in lower resource setting is another undeniable fact. Visual inspection with acetic acid and even simple examination of cervix may yet have a role as important screening tool in low resource setting.

Keywords: Cervical Cancer screening, Visual Inspection with acetic acid, Pap smear.
\end{abstract}

\section{Introduction}

Cervical cancer is a major health problem in India. Though data from the 20 populations based cancer registries in India indicate a steady decline in cervical cancer incidence rates over the last two decades, it still occupies number two position and the risk of disease is still high ${ }^{1}$. Since the introduction of cervical cytology in the United States in the mid- $20^{\text {th }}$ century, cervical cancer which was once the most frequent cause of female cancer deaths now ranks $14^{\text {th }}$ for cancer deaths ${ }^{2}$. This reduction is through widespread cervical cancer screening bringing about an increase in detection of invasive cancer at early stages and detection and treatment of pre-invasive lesions, which reduce the overall incidence of invasive cancer. One in every five women in the world suffering from cervical cancer belongs to India which has the largest burden of cervical cancer patients in the world ${ }^{4}$. Cervical cancer hits the 
lower socioeconomic strata the hardest. Lack of effective screening programs compounded by lack of facilities for such screening programs contribute to late detection and subsequently high incidence and mortality. Cervical cancer screening has successfully decreased cervical cancer incidence and mortality. Various effective screening tools are available but it requires good infrastructural support. An attempt at evaluation of the role of pap smear, visual inspection with acetic acid in low resource setting has been done in this study.

\section{Objective}

To compare simple examination of cervix with Visual inspection with acetic acid and pap smear for cervical cancer screening in low resource setting

\section{Methods}

The study was carried out as a part of free health camps from 8 villages around Imphal. Women age ranging from 20 years to 70 years from based on convenience were subjected to per speculum examination, Visual inspection with acetic acid and pap-smear, in that order.

These women were given awareness of cervical cancer and then the women who were keen to get it done were subjected to the test.

After explaining the procedure, all the cases who gave written consent were subjected to visual examination and then pap smear sample taken followed by visual inspection with acetic acid.

VIA results were interpreted as positive or negative.

Pap smear reported according to The Bethesda System:

- Atypical squamous cells

- Atypical squamous cells of undetermined significance (ASC-US)

- Atypical squamous cells - cannot exclude HSIL (ASC-H)

- Low grade squamous intraepithelial lesion (LSIL)
- High grade squamous intraepithelial lesion (HSIL)

- Squamous cell carcinoma

- Atypical Glandular Cells not otherwise specified (AGC-NOS)

- Atypical Glandular Cells, suspicious for AIS or cancer (AGC-neoplastic)

- Adenocarcinoma in situ (AIS)

Results

300 women were examined.

\begin{tabular}{|l|c|c|c|}
\hline VIA & Negative & 207 & $69 \%$ \\
\hline n=300 & Positive & 93 & $31 \%$ \\
\hline $\begin{array}{l}\text { Pap with } \\
\text { VIA } \\
\text { positive } \\
\text { n=93 }\end{array}$ & NILM & 71 & $76.3 \%$ \\
\hline & $\begin{array}{l}\text { NILM with } \\
\text { koilocytes }\end{array}$ & 3 & $3.2 \%$ \\
\hline & LSIL & 6 & $6.4 \%$ \\
\hline & HSIL & 2 & $2.1 \%$ \\
\hline & ASCUS/ASC-H & 6 & $6.4 \%$ \\
\hline & AGC-NOS & 2 & $2.1 \%$ \\
\hline & $\begin{array}{c}\text { Squamous cell } \\
\text { carcinoma }\end{array}$ & 2 & $2.1 \%$ \\
\hline & Adenocarcinoma & 1 & $1.07 \%$ \\
\hline
\end{tabular}

\begin{tabular}{|l|c|c|c|}
\hline $\begin{array}{l}\text { Pap with } \\
\text { VIA negative } \\
\text { n=40 }\end{array}$ & LSIL & 9 & $22.5 \%$ \\
\hline & HSIL & 2 & $5 \%$ \\
\hline & ASCUS/ASC-H & 29 & $72.5 \%$ \\
\hline
\end{tabular}

Comparison of VIA and Pap:

\begin{tabular}{|l|c|c|c|}
\hline VIA & Pap & Pap & Total \\
\hline & positive & negative & \\
\hline positive & 15 & 78 & 93 \\
\hline negative & 40 & 167 & 207 \\
\hline
\end{tabular}

Simple examination showed 2 clinically suspicious cases for cancer cervix.

Of 93 VIA positive cases noted, $76.3 \%$ were negative for intraepithelial lesion or malignancy. VIA interpretation were negative for $22.5 \%$ LSIL, $5 \%$ HSIL and $72.5 \%$ for ASCUS/ASC-H, which is higher than that of VIA positive ASCUS/ASC$\mathrm{H} 6.4 \%$. VIA positive for AGC-NOS and NILM with Koilocytes stood at $2.1 \%$ and $3.2 \%$ respectively.

Sensitivity of VIA $=27.27 \%$

Specificity of VIA $=68.1 \%$

Predictive value of positive test $=16.1 \%$

Predictive value of negative test $=80.67 \%$ 


\section{Discussion}

In an apparently normal looking cervix, simple visualisation does not reveal much. Cervical ectopy, chronic cervicitis feature or even polyp, etc are easily visualised but does not give information on presence of precancerous lesion. Florid cancer of cervix are apparent by the ulcerative/proliferative appearance.

The recommended age in updated guidelines from USPSTF is 21-65 years, and while the intention was to follow that age group, the study included women 20 years and beyond 65 years due to their keenness to get the test done after the awareness program. In the study, while sensitivity of VIA is found to be low, the specificity was much more. The positive predictive value was much lower, hence a positive result needs excluding other causes of VIA positive result. In a VIA negative cases, the predictive value is $80.67 \%$, which implies, that for VIA negative cases, the chances of not having precancerous lesion of the cervix is $80.67 \%$. The findings differed from most studies.

Manju Talathi et $\mathrm{al}^{4}$ did a study comparing VIA and Pap, which showed that though specificity of VIA is less (48.4\%) as compared to Pap specificity $(70 \%)$, sensitivity of VIA $(100 \%)$ is almost comparable with sensitivity of Pap (90.2\%) and VIA has $100 \%$ NPV (negative predictive value) in this study.

Ghazala et $\mathrm{al}^{5}$ in their study cited VIA had significantly higher sensitivity than Pap smear $75.8 \%$ vs. $61.1 \%$ in biopsy positive cases. While Specificity of VIA in their study was $99.1 \%$ vs. $99.4 \%$ for Pap smear.

Ashish Kumar Bhattacharya et $\mathrm{al}^{6}$ in their study cited sensitivity of VIA to be $89 \%$ (versus Pap smear, which had 52\%) while the specificity of VIA was $87 \%$ (versus Pap smear, which had a specificity of 95\%). Thus, VIA showed higher sensitivity compared to Pap smear, whereas VIA had lower specificity compared to Pap smear. Lower specificity of VIA when compared to Pap smear was due to the high incidence of suspected aceto white epithelium, which might be inflammation, immature metaplasia or latent HPV infection.

The differences may be explained by technical issues and differences in subjective interpretation or other cervical pathology or conditions.

\section{Conclusion}

Despite existence of national guidelines the screening coverage in India is appalling and is mainly attributed to inequality between infrastructure, resources and outsized population. VIA is a simple procedure compared to pap smear, requiring minimal resources and technical knowhow. Screening methods involving detection of HPV, colposcopy while very effective in detection of cases, requires lots of resources. Simple visualisation of cervix have no role except maybe detect overt cancer cases. VIA as alternative to Pap smear for mass screening as preventive method may yet have a role in low resource settings. However, as seen from the response after spreading awareness, effective screening on mass scale may yet be possible by inculcating a health checking behaviour.

\section{References}

1. National Cancer Registry Programme. 4. Three year report of population based cancer registries 2006-2008. New Delhi: ICMR; 2010.

2. Siegel R, Naishadham D, Jemal A. Cancer statistics, 2012. CA Cancer J Clin2012; 62:10-29.

3. Government of India - World Health Organization Collaboration Programme 2004-2005. Guidelines for cervical cancer screening programme; 2006.

4. Talathi $\mathbf{M}$ et al. Int $\mathbf{J}$ Reprod Contracept Obstet Gynecol. 2016 Oct;5(10):33843389.

5. Ghazala Mahmud, Nasira Tasnim, Saima Iqbal. Comparison of Visual Inspection with acetic acid and Pap smear in cervical cancer screening at a tertiary care hospital. JPMA 63: 1013; 2013. 
6. Ashish Kr Bhattacharya, Jyan Dip Nath, Harajyoti Deka. Comparative study between pap smear and visual inspection with acetic acid (via) in screening of CIN and early cervical cancer. J Midlife Health. 2015 Apr-Jun; 6(2): 53-58. 